\title{
PEDAGOGIA HISTÓRICO-CRITICA E LUTA DE CLASSES NA EDUCAÇÃO ESCOLAR
}

\author{
Resenha do livro: \\ SAVIANI, Dermeval e DUARTE, Newton. Pedagogia histórico-critica e luta de classes \\ na educação escolar. Campinas: Autores Associados, 2012. 184 p
}

\section{Por Lucia Mara de Lima Padilha ${ }^{1}$}

O livro Pedagogia Histórico - Critica e Luta de Classes na Educação Escolar, de autoria dos professores Dermeval Saviani e Newton Duarte, dividido em sete capítulos, aborda o debate acerca da participação do trabalho educativo escolar no processo de superação da sociedade burguesa, processo esse que se dá por meio da luta permanente pela efetivação das máximas possibilidades de socialização dos conteúdos científicos, artísticos e filosóficos. Os autores elegem como tese central a assertiva de que a luta pela escola pública coincide com a luta pelo socialismo, e que perante a gravidade mundial é preciso ter atitudes claras e respostas concretas em termos de mobilização coletiva por transformações sociais radicais. $O$ acesso ao conhecimento dá-se de maneira profundamente desigual e seletiva, porém, tudo camuflado pelo discurso de respeito às diferenças culturais, pelo fetichismo da democratização do acesso ao conhecimento e pela subordinação dos objetivos da educação escolar a uma lógica de permanente esforço do indivíduo para se adaptar às mudanças constantes das condições de vida e de trabalho. Para os autores, a luta pela plena socialização do conhecimento pela escola, na sociedade burguesa, não revolucionará a sociedade, pelo simples fato de que a escola não tem o poder de mudar a sociedade, mas acreditam que a revolução é uma ação humana, e como tal, depende da consciência, sendo a revolução não um processo espontâneo, mas movido pela classe trabalhadora conscientemente organizada. Nesse sentido, desenvolver o trabalho educativo na perspectiva de superação do modo de produção capitalista requer uma pedagogia de inspiração marxista, e este livro, soma-se aos esforços que vêm sendo realizados coletivamente para a construção da pedagogia histórico - crítica.

No capítulo, A formação Humana na Perspectiva Histórico-ontológica, Saviani e Duarte discutem a definição da educação como formação humana e em que ela se consiste. Analisam o homem, como um ser situado e determinado pelas condições do meio natural e cultural, nos seus aspectos pessoais e intelectuais. No aspecto pessoal, isto é, da liberdade, o homem mostra-se capaz de aceitar, intervir e modificar, deste modo, ele poderá intervir na vida de novas gerações para educá-las. No entanto, a educação continua sem ser legitimada, pois, com que direito o educador interfere na vida do educando? $\mathrm{Na}$ análise intelectual, o homem é capaz de transcender a situação, assim como pontos de vista pessoais, para se colocar na perspectiva universal entrando em comunicação com os outros e reconhecendo suas condições situacionais. Funda-se aí a legitimidade da educação, que emerge, como uma comunicação entre pessoas livres em graus diferentes de maturação humana. A formação humana coincide, nessa acepção, com o processo de promoção humana, levado a efeito pela educação. Desta forma, a filosofia da educação cumpre o papel preliminar de estabelecer a própria identidade da educação, sua tarefa consiste em uma reflexão radical, rigorosa e de conjunto sobre os problemas que a realidade apresenta. A filosofia trata daquilo que é a qualidade humana por excelência, isto é, o pensamento, razão pela qual interessa a todos os homens. Mas o conteúdo da filosofia é a história, ou seja, a produção da própria existência humana no tempo. Assim, a filosofia e a história da educação constituem o núcleo duro da formação do educador. Dando continuidade a esse 
capítulo, os autores esboçam uma fenomenologia de uma época atual, constatando que as ideias atualmente hegemônicas na educação se centram na crítica à razão e às noções de verdade e objetividade. As ideias que parecem ser hegemônicas se manifestam como expressão de crise na medida em que não se afirmam positivamente, mas se expressam como negação daquilo que é denominado como sendo a metafísica do sujeito, característica da modernidade. Daí a crítica à razão, à consciência, às noções de verdade e de objetividade, a substituição da epistemologia pela linguística e da lógica pela semântica, chegando-se a conclusão de que não faz sentido se falar em conhecimento das coisas, já que tudo se resume a "jogos de linguagem". A esse neopragmatismo que, na tentativa de opor-se a metafísica, acaba por ser metafísico reduzindo tudo à linguagem, os autores, a partir de uma reflexão histórico - ontológica sobre a formação humana contida nos Manuscritos Econômicos e Filosóficos (1844), afirmam que é preciso restabelecer o entendimento de que o pensamento de Marx é caracteristicamente antimetafísico, manifestando-se provavelmente como a forma mais acabada de um modo de filosofar que unifica, na história, o conteúdo e a forma da filosofia. É assim, uma filosofia ao mesmo tempo histórica e historicizadora, em que estão em causa não os sujeitos abstratos, mas os indivíduos reais, sujeitos históricos que se constituem como síntese de relações sociais.

No capítulo, Lukács e Saviani: a ontologia do ser social e a pedagogia histórico crítica, Duarte parte da afirmação que na abordagem materialista histórico - dialética, o estudo ontológico do ser social não prescinde do estudo da gênese histórica da especificidade da sociedade perante a natureza. O ser humano é antes de tudo um ser vivo e a sociedade só pode existir em permanente intercâmbio com a natureza. No que diz respeito à educação em geral e à educação escolar em particular, um dos desafios que estão postos para uma teoria educacional marxista é o da construção de uma ontologia da educação. Assim, adotando a concepção de Lukács, a educação adquire real significado como objeto da reflexão ontológica somente quando analisada como um dos complexos que compõem a sociedade. Mas como o ser da sociedade é histórico, a essência ontológica da educação só pode ser apreendida numa perspectiva historicista. Trata-se da análise dos processos historicamente concretos de formação dos indivíduos e de como, por meio desses processos vai se definindo, no interior da vida social, um campo específico de atividade humana, o campo da atividade educativa. $\mathrm{O}$ autor constata que são poucas as tentativas de aproximação entre os estudos de Lukács no campo de uma ontologia marxista do ser social e os estudos de Saviani no campo da pedagogia histórico - crítica. Uma das características basilares dos trabalhos de Saviani é justamente a busca da superação da dualidade entre a essência e historicidade, característica essa que fez o pensamento desse educador destacar-se de outras teorias críticas sobre a educação brasileira. Para que uma teoria marxista da educação possa ser também uma pedagogia marxista, é necessário assumir um posicionamento afirmativo sobre o que significa educar seres humanos hoje. Os elementos para uma ontologia da educação na obra de Saviani são justamente aqueles nos quais ele apresenta um posicionamento afirmativo sobre a essência do ato educativo. Nesse sentido, o autor analisa momentos da obra de Saviani que se podem constituir em elementos para uma ontologia da educação.

No capítulo intitulado: Marxismo, Educação e Pedagogia, Saviani aborda o tema da relação entre marxismo e educação pelo ponto de vista da relação mais específica entre a teoria marxista e a pedagogia socialista. Aborda a concepção marxista de homem, as contradições da concepção burguesa de educação, a concepção socialista de educação, educação socialista, politécnica e o panorama atual, educação e sociedade de classes com seus desafios, a pedagogia histórico-crítica e os desafios pedagógicos no contexto brasileiro. Começando pelo significado do conhecimento em Marx como base para o 
entendimento tanto da teoria marxista da educação como da pedagogia socialista de inspiração marxista, o autor coloca que, para Marx o movimento global do conhecimento compreende dois momentos. Parte-se do empírico, isto é, do objeto na forma como se apresenta à observação imediata, neste momento inicial, o objeto é captado numa visão caótica, sem clareza do modo como ele é constituído. Partindo dessa representação primeira do objeto, chega-se por meio da análise aos conceitos, às abstrações, às determinações mais simples. Uma vez atingido esse ponto, percorre-se o caminho inverso chegando pela via da síntese, de novo ao objeto, agora entendido não mais como representação caótica, mas como uma totalidade de determinações e relações. Assim compreendido, o processo de conhecimento é, ao mesmo tempo, indutivo e dedutivo, analítico-sintético, abstrato-concreto, lógico-histórico. Deve-se distinguir, portanto, o concreto real do concreto pensado. Vê-se, pois, que estamos diante de uma concepção realista, em termos ontológicos, e objetivista, em termos gnosiológicos. Assenta-se, portanto, em duas premissas. 1- As coisas existem independentemente do pensamento, com o corolário, 2- A realidade é cognoscível, com o corolário. Continuando sua escrita, o autor aborda questões específicas da teoria marxista e a educação, destacando que, Marx não se ocupou direta e especificamente da elaboração teórica no campo da educação, mas que não faltaram esforços, seja para identificar no conjunto de sua obra passagens referente à educação, seja para extrair das análises marxianas sobre a história, a economia e a sociedade derivações de sentido para a educação. Quanto às passagens dos escritos de Marx referidas à educação, o autor destaca que elas se encontram clara e didaticamente na obra de Manacorda, primeiro no livro IL Marxismo e L'educazione e posteriormente no livro Marx e a Pedagogia Moderna, no qual ele distingue três momentos, nos quais Marx fala sobre a educação. Quanto às derivações de sentido para a educação, obtidas a partir da consideração do conjunto da obra de Marx e Engels, quem talvez melhor exemplifique esse esforço é Suchodolski que chegou a publicar em 1961, o livro "Teoria Marxista de La educación". O autor concluiu seu texto abordando questões sobre a pedagogia socialista e a pedagogia concreta, enfatizando que, uma pedagogia concreta é aquela que considera os educandos como indivíduos concretos, e que para a construção de uma pedagogia inspirada no materialismo histórico não basta recolher passagens das obras de Marx e Engels, mas implica na apreensão da concepção de fundo que caracteriza o materialismo histórico.

No capítulo A Pedagogia Histórico - Crítica e o Marxismo: Equívocos de (mais) uma crítica à obra de Dermeval Saviani, escrito por Duarte, Ferreira, Malanchem, e Muller, os autores tem como tema central a tese de Lazarini (2010), na qual ele, apoiandose na crítica de Lessa (2007), se propõe a mostrar que a obra de Saviani e a pedagogia histórico-crítica no seu conjunto apresenta equívocos fundamentais. Lazarini afirma que Saviani ao invés de se posicionar criticamente em relação à lógica do capital, defenderia uma educação escolar centrada no ensino dos processos de trabalho, ou seja, a pedagogia histórico-crítica defenderia a domesticação dos indivíduos ao trabalho alienado. Apoiado em Mészáros e Tonet, Lazarini esforça-se por negar qualquer intenção imobilista, seja de suas análises, seja daquelas nos quais se apoia. Lazarini apresenta a distinção entre a produção material e não material como se ela tivesse sido inventada por Saviani como uma alternativa às categorias marxianas, de trabalho produtivo e trabalho improdutivo. Contrariamente a Marx, Lazarini e Lessa se recusam a aceitar a existência de uma produção não material, pois para eles seria uma produção que resultaria num produto inexistente. Para os autores, o equívoco não está em Saviani, mas sim na identificação feita por Lessa e adotada por Lazarini, entre o que é material e o que é objetivo. Tanto Lessa quanto Lazarini caem naquilo que acusam em Saviani, ou seja, são eles que não conseguem entender a dialética entre materialidade e idealidade, bem como entre 
objetividade e subjetividade. A tese de Lazarini apresenta a fragilidade da argumentação crítica como consequência do caráter não dialético de sua compreensão do pensamento de Marx, pois emprega a designação "materialismo histórico" em vez de "materialismo histórico e dialético". Ele repete várias vezes ao longo da tese que um dos equívocos de Saviani seria o de recusar a analisar a atividade do professor à luz dos conceitos de trabalho produtivo e trabalho improdutivo, que ao invés de fazer uma análise crítica do trabalho na sociedade capitalista, Saviani opta por uma via crítica e idealista, ao tomar o trabalho como modelo para a formação humana e ao definir a atividade educativa como trabalho não material. Segundo os autores, Saviani explica é que a categoria de trabalho não material mostra-se mais adequada à tentativa de compreensão do significado do trabalho em educação, isto é, à caracterização da especificidade da educação escolar perante outras modalidades da prática social. Saviani não está afirmando que as categorias de trabalho produtivo e improdutivo não se aplicam ao trabalho do professor, mas que elas não explicam a especificidade desse trabalho. Quando Saviani parte da distinção marxiana, no campo de produção não material, entre as atividades nas quais o produto se separa do ato de produção e aquelas nas quais o produto não se separa do ato de produção, seu objetivo não é negar a existência de alienação no trabalho do professor na sociedade capitalista, mas sim caracterizar a especificidade da atividade educativa escolar. Lazarini faz uma leitura inegavelmente parcial e distorcida da obra de Saviani, pois escreve aproximadamente 500 páginas dedicadas a uma análise crítica da obra de Saviani, na qual não analisou, nem mesmo citou o conceito de trabalho educativo. Mas não foi somente o conceito de trabalho educativo que Lazarini preferiu se esquivar como também da própria utilização de conceitos de trabalho produtivo e improdutivo na análise da atividade educativa, ele critica Saviani por não empregar esses conceitos, mas o fato é que ele mesmo não o faz. Sua recusa em considerar a especificidade do trabalho educativo levou à incompreensão do papel da socialização do conhecimento no processo de superação do capitalismo. Segundo os autores, somente uma imensa vontade de não entender o que está escrito levaria alguém a interpretar o raciocínio de Saviani como se ele estivesse afirmando que a escola pública pode alcançar na sociedade capitalista a plena socialização do saber sistematizado e que, quando isso ocorrer, a escola terá produzido a passagem do capitalismo para o socialismo. O que Saviani afirma é que a luta por um sistema público de ensino que realize a função da escola, que é a de socializar o saber sistematizado, entra em contradição com a lógica da sociedade capitalista e que, a luta pela escola pública só faz realmente sentido quando é parte da luta pelo socialismo. E a socialização do conhecimento sistematizado é necessária para a organização da classe trabalhadora em sua luta revolucionária contra as relações capitalistas de produção.

No capítulo Debate sobre educação, formação humana e ontologia a partir da questão do Método Dialético, Saviani escreve sobre sua participação na mesa redonda realizada no V Encontro Brasileiro de Educação e Marxismo. Inicia respondendo as críticas feitas a ele por Lazarini em sua tese de doutorado defendida em 2010. A referida tese retorna as criticas, feitas por Sérgio Lessa, Ivo Tonet e Paulo Sérgio Tumolo, além de recuperar outros estudos críticos no final dos anos de 1980 e início de 1990 . Talvez o que ela traga de novo seja o fato de reunir num só trabalho um conjunto de críticas formuladas de forma mais ou menos esparsa, além do caráter bombástico com que as denúncias são apresentadas. Para Saviani, a grande surpresa foi o fato de ter sido produzida ao longo de cinco anos, sem que nenhum contato fosse feito com ele. Deste modo, parece ter havido um problema metodológico da pesquisa, porque seu autor elegeu um objeto, mas não tomou nenhuma iniciativa em conhecê-lo diretamente. Isso permitiria ao autor da tese assegurar-se melhor de seus argumentos tornando suas críticas mais consistentes. Saviani, 
afirma não ter sido tratado como um companheiro de mesmo campo teórico-políticoideológico a quem se endereçam críticas para fazê-lo avançar ou para corrigir os desvios detectados em sua apropriação da teoria, mas sim como um inimigo a abater. Saviani se recusa a estudar um autor por ele mesmo e se debruçar sobre seus escritos tentando decifrá-los para expor o núcleo de seu conteúdo, mas recorre dos autores para poder compreender melhor a realidade e responder aos problemas enfrentados. Abordando o tema da mesa Saviani começa sua exposição com a discussão acerca das dificuldades em se colocar em prática o método desenvolvido por Marx apresentando os três conceitos básicos presentes no enunciado da mesma: o primeiro é educação; o segundo, formação humana; e o terceiro é ontologia. Partindo de uma análise formal, o autor diz ser possível considerar que, se os termos educação e formação humana são sinônimos no plano formal, quando passamos ao plano concreto essa sinonímia já não é tão evidente. Com efeito, pode ocorrer que no plano concreto a educação se processe não como formação do homem, mas como sua deformação. Para Saviani, tendo em vista que é o trabalho que define a essência humana, pode-se considerar que está aí a referência ontológica para se compreender e reconhecer a educação como formação humana. $\mathrm{O}$ homem se constitui como homem pelo seu trabalho, e esse processo de produção do homem, que coincide com seu processo de formação, vai se complexificando ao longo da história dando origem a diversas modalidades de trabalho, entre as quais assume particular relevância a diferenciação entre trabalho material e não material. Citando as categorias dialéticas da totalidade, contradição e ação recíproca, aplicadas por Marx, Saviani destaca que a controvérsia instaurada pelo grupo que vem se insurgindo contra a pedagogia histórico-crítica em nome do marxismo gire basicamente em torno dela.

O capitulo intitulado Luta de Classe, Educação e Revolução, trata-se de uma entrevista para Germinal: marxismo e educação em debate, com Newton Duarte. Para ele, na perspectiva do marxismo, a revolução é um processo de construção da sociedade. A revolução tem uma direção e requer a busca da compreensão das mediações entre o presente e o futuro em longo prazo. Não existe ainda uma cultura plenamente universal, pelo simples fato de que a humanidade não está ainda plenamente unificada. Para Duarte a historia até aqui percorrida acumulou elementos importantíssimos para a construção dessa cultura e será necessário incorporar à sociedade socialista toda a riqueza material e espiritual até aqui criada, para poder avançar no processo de superação da humanidade dividida. A resolução de problemas básicos como a eliminação social da fome e do analfabetismo e como a criação das condições materiais básicas que assegurem a vida não é a meta da revolução. Mas a concretização, na vida de todos os seres humanos, das máximas possibilidades de desenvolvimento multifacetado. Isso só ocorrerá quando o trabalho deixar de ser uma atividade alienada, quando for superada a divisão de trabalho manual e intelectual. Alguns marxistas no Brasil tem afirmado que atividade educativa não é trabalho, esta é uma leitura reducionista de marx. Todavia, o autor alerta que a categoria trabalho na obra de Marx jamais se reduziu à produção material. Então discorre pela obra de Marx para elucidar ainda mais esta afirmativa. Para Duarte a escola é o lugar por excelência da luta pela socialização do conhecimento. Há marxista que afirma que o conhecimento não é um meio de produção e que, portanto, a luta pela socialização do conhecimento não é parte da luta pela socialização da propriedade dos meios de produção. Este raciocínio, para o autor, é um equívoco por duas razões: primeiro por que ao longo dos escritos de Marx encontra-se uma clara análise do processo de objetivação do conhecimento nos produtos do trabalho e nos meios empregados no processo de trabalho. Separar os meios de produção do conhecimento que permite a existência deles é assumir uma atitude fetichista. Duarte faz uma crítica novamente a alguns marxistas 
contemporâneos por afirmarem que nada se pode fazer na esfera do Estado em termos e luta contra o capital. Esta para ele é uma visão bem pouco dialética, como se não existissem contradições no Estado burguês. Por sua vez, este grupo, o qual critica Newton, defende a educação não formal que estaria fora da influência do Estado e do capital. Esta também é uma visão pouco dialética. O ponto de Acordo para a educação pública, segundo Duarte é o pensamento do grande educador marxista brasileiro Dermeval Saviani. Quanto às políticas dos governantes, para Duarte não houve ruptura com a hegemonia da pedagogia do aprender a aprender entre a política educacional do governo Fernando Henrique e o governo Lula. Quanto à natureza do trabalho educativo, enquanto espaço emancipatório, com agendas mundiais por metas direcionadas ao mundo das organizações, Duarte afirma que há um ataque orquestrado à natureza do trabalho educativo. Uma escola ensinando de verdade aos filhos da classe trabalhadora é algo que oferece perigo a classe dominante.

No capitulo História, Trabalho e Educação: comentários sobre as controvérsias internas ao campo Marxista, Saviani, se propõe a levantar a discussão da questão: por que as esquerdas, de modo geral, e os marxistas, em particular, timbram em cultivar divergências sobre as mais variadas questões, sejam elas de ordem teórica ou de ordem prática? Num primeiro momento o autor aborda a questão referida aos clássicos do marxismo, analisando o fenômeno das divergências interpretativas de forma positiva levando em conta que a análise crítica e o debate das posições são um elemento integrante da tradição marxista, constituindo-se num procedimento crucial para refinar a teoria e as estratégias revolucionárias e para fazer avançar o conhecimento. Observa que os clássicos do marxismo, com destaque para Marx, Engels, Lênin e Gramsci, guiaram-se sempre por dois princípios: 1- a diferenciação entre a perspectiva proletária e aquela dos burgueses e pequeno - burgueses progressistas; 2 - a firme união entre as forças que buscam expressar e fazer avançar a luta dos trabalhadores. Para Saviani, os esforços que todos os integrantes do campo marxista devem fazer é o de unirem-se em torno da luta pela transformação da sociedade distinguindo claramente a perspectiva proletária daquela dos burgueses e pequenos - burgueses progressistas. Nesse empenho, cabe considerar as diferenças de cada um, explorando aspectos distintos da teoria marxista e das estratégias de luta, porém fazendo convergir sempre para o objetivo do reforço da união na árdua luta contra as forças dominantes da sociedade capitalista. No marxismo a historia é uma categoria central, por isso essa concepção de materialismo histórico. Tudo que o homem é o é pelo trabalho. Saviani fala que são muito bem vindos os esforços para esclarecer o significado marxista do conceito de trabalho, tarefa a qual se dedicou. Reafirma que na sociedade capitalista, em que o trabalho assume a forma da produção de valores de troca, ele não pode ser considerado como princípio educativo. Para o autor se faz necessário distinguir nesse debate sobre o trabalho como princípio educativo dois aspectos: a) questão teórica e b) a questão estratégica. Desta forma, ele esclarece, com base nos clássicos do marxismo, o significado teórico do trabalho como princípio educativo.

\footnotetext{
${ }^{1}$ Mestre e Doutoranda em Educação (linha de pesquisa História e Políticas Educacionais) pela Universidade Estadual de Ponta Grossa /UEPG - PR.
} 